\title{
Course-Based Learning Outcomes as the Foundation for Assessment of Graduate Attributes - an Update on the Progress of Memorial University
}

\author{
Darlene Spracklin-Reid, P.Eng \\ Senior Instructional Designer \\ Distance Education, Learning and Teaching Support, Memorial University \\ darlenesr@mun.ca \\ Andrew Fisher, P.Eng \\ Associate Dean (Undergraduate Studies) \\ Faculty of Engineering \& Applied Science, Memorial University \\ adfisher@mun.ca
}

\begin{abstract}
In 2010, the Canadian Engineering Accreditation Board (CEAB) began reviewing programs for progress toward assessment of graduate attributes. This represented a significant change from traditional inputs-based to outcomes-based accreditation. As engineering schools across Canada implement various approaches to meeting the CEAB requirements, this paper provides an update on the course-based learning outcomes approach taken by the Faculty of Engineering and Applied Science at Memorial University.
\end{abstract}

\section{Introduction}

The development of comprehensive learning outcomes for all core courses in the engineering program is the foundation for Memorial University's approach to the Canadian Engineering Accreditation Board's (CEAB) outputs-based accreditation [1]. The graduate attributes as defined by the CEAB are our program outcomes. The assessment of these program outcomes is achieved through the assessment of course-based learning outcomes that contribute to attribute development.

Graduate attributes are a composite of knowledge, skills and attitudes that are developed and demonstrated at various levels throughout the engineering program [2]. Measureable learning outcomes allow for the assessment of graduate attributes as they develop and they are an important component of the quality assurance and continual improvement process. Using a complete and comprehensive set of learning outcomes, deficiencies in acquiring graduate attributes can be identified and problems can be addressed in a timely way. A set of CEEA13; Paper 43 -1 of 4 comprehensive learning outcomes is used to build curriculum maps that can provide the detail required to identify areas for improvement in the program. Curriculum mapping is effective in operationalizing outcome-based education. Curriculum maps are important quality assurance tools and they have a role in determining whether the curriculum meets specified standards and is aligned with the expected learning outcomes [3].

Documenting course-based learning outcomes identifies opportunities for improvement that may not be obvious using the top-down approach of assigning graduate attributes or broad indicators to courses. Using course-based learning outcomes, we are identifying opportunities to implement small changes that have big impacts. This approach allows the faculty to be "intentional" about the development of graduate attributes.

Faculty, staff and students work collaboratively to develop learning outcomes, assessment techniques and curriculum maps. Based on these, graduate attributes are identified, assessed and continuous improvement is facilitated. The goal is not only to exceed the CEAB requirements, but also to use the process as an opportunity to reflect on, encourage and implement best-practices in teaching and learning.

\section{Graduate Attributes as Program Outcomes}

The change from inputs-based to outcomes-based accreditation doesn't mean that Canadian engineering schools have been getting it all wrong. However, it does mean that we are changing the lens through which we examine our programs. Memorial's approach to meeting the CEAB's requirements requires taking a detailed look at what we have been 
doing, evaluating that against the CEAB's graduate attributes and moving forward by addressing specific opportunities for improvement.

Graduate attributes are program outcomes, and program outcomes are built upon course outcomes. Authentic assessment of graduate attributes can be achieved if they are linked to course based outcomes that are measureable indicators of learning and skill acquisition.

\subsection{Developing Learning Outcomes}

For each course in Memorial University's Faculty of Engineering and Applied Science, specific, achievable and measureable learning outcomes are being developed. These learning outcomes are statements that describe what a student will know, or what they will be able to do, upon successful completion of the course. These learning outcomes form a comprehensive picture of what students are learning, at what level they are learning it, and where that learning is occurring in the program.

The development of learning outcomes has been a collaborative process based on accepted learning theories such as Bloom's Revised Taxonomy [4][5]. As of May 2013, learning outcomes have been developed for approximately $65 \%$ of the courses across all engineering disciplines, with $100 \%$ of courses in Process Engineering having measurable learning outcomes. Process Engineering was a priority for learning outcome development because it was being accredited for the fist time in the winter of 2013.

Teaching and learning communities are comprised of students, faculty and staff. In Memorial's outcomes-oriented teaching and learning community, these parties work together to identify the knowledge and skills students must possess in order to demonstrate the required graduate attributes [6]. In Process Engineering, a teaching and learning community was established to collaborate on developing learning outcomes and facilitate their assessment. Learning outcomes were developed for each course by individual professors and shared with the discipline group and instructional design staff for input. The group reviewed the outcomes collectively, offering and incorporating suggestions and feedback. The learning outcomes belong to the process engineering discipline, and can be reviewed, updated and edited within the group at any time.

With emphasis placed on the learning outcomes, and not the learning process, academic freedom is maintained. Developing learning outcomes together did lead to discussions about the learning process however seeking and receiving input was a voluntary process.

With ownership and control of the development and maintenance of the outcomes remaining within each discipline, the flexibility to respond to required changes is facilitated while maintaining accountability to the $\mathrm{CEAB}$ requirements. Teaching and learning communities have been found to be effective in establishing and changing curricula [7]. In Process Engineering, accreditation feedback suggested a reordering of some learning outcomes and this proved to be a simple change that the faculty could collectively make.

\subsection{Assessing Learning Outcomes}

Learning outcomes must be measurable so as course-based learning outcomes are developed, so too are associated assessments. Assessments are learning activities or exercises designed to obtain evidence of student achievement of learning outcomes. Common engineering assessments include laboratory work, projects, assignments, final examinations, or presentations [8].

Support for the design of assessment tools such as ePortfolios and rubrics is provided by Instructional Designers and Teaching Consultants from Memorial University's Distance Education Learning and Teaching Support (DELTS) division, and is informed by student feedback through surveys and focus groups. Teaching and assessment toolkits for each graduate attribute have been developed to support faculty members in Process Engineering. The toolkit is the product of a collaborative effort by faculty, staff and students, and it consists of multi-media resources accessible through an online course shell.

For example, the toolkit section for CEAB's individual and teamwork graduate attribute has multimedia content supporting the development of leadership and effective team work skills, along with assessment tools including rubrics, self-assessments, suggested assignments, and learning activities. The content was developed, and continues to be developed, collaboratively. Including students in the process allowed them to make contributions by providing feedback and suggestions on ways they can best demonstrate their knowledge and skills. Content is available to be used as-is, or modified and reposted to share.

By linking assessments to course-based learning outcomes, we are able to monitor the development of graduate attributes as it occurs, allowing for formative assessments to guide that development. Support for formative assessment is provided to faculty via the 
toolkit and supported by regular meetings of the teaching and learning community and one-on-one sessions with the instructional designer. Rather than only examining the final product, assessing graduate attributes in a formative way creates opportunities for improvement as students progress through the course and the program.

\subsubsection{Assessing outcomes using ePortfolios}

The Faculty of Engineering and Applied Science at Memorial University is using ePortfolios to capture learning that is occurring throughout the program. The ePortfolio is introduced in ENGI 3101, The Engineering Workplace, early in the program. This is the first semester after the students choose their individual disciplines. Students learn how to use the basics tools associated with an ePortfolio and are introduced to structured, reflective learning.

Throughout the program, students add samples of their work, or artefacts, along with reflective responses in a guided, structured way. These artefacts include samples of work completed in academic courses, on work terms, in extra-curricular activities or in volunteer capacities.

The ePortfolio is revisited in ENGI 7102, The Engineering Profession. In this course, students are able to reflect on their own development with particular emphasis on their development of the CEAB graduate attributes.

Using ePortfolios as an assessment tool allows for recognition of learning that occurs outside of the classroom (e.g. work terms, student society leadership, EWB, etc). By bringing these aspects into focus, other opportunities for student engagement are beginning to emerge.

\subsection{Linking Graduate Attributes to Learning Outcomes and Assessments}

As specific course-based learning outcomes and assessments are created, they are linked to graduate attributes in our database approach to curriculum mapping. As the learning outcomes are measured, graduate attributes are being measured.

The database, and the curriculum map it informs, is searchable by graduate attribute. A search for a specific graduate attribute tells the user the courses in which that attribute is being developed, the specific learning outcomes or indicators associated with that graduate attribute, and how those outcomes, and therefore the graduate attribute, are being measured.

This bottom-up approach ensures that a comprehensive curriculum map is created. We can track graduate attributes as they develop, and measure that development as it occurs. It allows for quality assurance of the program, and facilitates continuous improvement.

In Process Engineering, the links that have been established among learning outcomes, graduate attributes, levels of learning and assessment tools are shared with the students as part of the standard course outline. Providing this information to students allows them to understand how individual learning outcomes and activities come together to form the bigger picture. Understanding how the pieces fit together enhances learning and improves student achievement [3].

Table 1: Sample learning outcomes, graduate attributes and assessments

\begin{tabular}{|l|l|l|}
\hline \multicolumn{1}{|c|}{ Learning Outcome } & $\begin{array}{c}\text { Graduate } \\
\text { Attribute and } \\
\text { Level }\end{array}$ & \multicolumn{1}{|c|}{$\begin{array}{c}\text { Method of } \\
\text { Assessment }\end{array}$} \\
\hline $\begin{array}{l}\text { Identify the role of } \\
\text { process engineering } \\
\text { in the community. }\end{array}$ & $\begin{array}{l}\text { GA08.1 } \\
\text { GA09.1 }\end{array}$ & $\begin{array}{l}\text { group activity, } \\
\text { reflective } \\
\text { ePortfolio posting }\end{array}$ \\
\hline $\begin{array}{l}\text { Create block flow, } \\
\text { process flow, piping } \\
\text { and instrumentation } \\
\text { diagrams. }\end{array}$ & $\begin{array}{l}\text { GA01.2, } \\
\text { GA04.2, } \\
\text { GA07.2 }\end{array}$ & $\begin{array}{l}\text { assignment, } \\
\text { midterm, lab }\end{array}$ \\
\hline $\begin{array}{l}\text { Detail a PFD, convert } \\
\text { units, and perform } \\
\text { material balances. }\end{array}$ & $\begin{array}{l}\text { GA05.2, } \\
\text { GA02.2 }\end{array}$ & labs \\
\hline $\begin{array}{l}\text { Communicate } \\
\text { technical information } \\
\text { in a clear and } \\
\text { effective manner. }\end{array}$ & $\begin{array}{l}\text { GA07.2, } \\
\text { GA08.1 }\end{array}$ & $\begin{array}{l}\text { presentation, } \\
\text { project, lab, } \\
\text { report }\end{array}$ \\
\hline $\begin{array}{l}\text { Understand your } \\
\text { learning style. }\end{array}$ & GA12.1 & $\begin{array}{l}\text { self-quiz, } \\
\text { ePortfolio }\end{array}$ \\
\hline
\end{tabular}

${ }^{1}$ GA09.1 means Graduate Attribute 9 at an introductory level.

GA01 A knowledge base for engineering

GA02 Problem analysis

GA03 Investigation

GA04 Design

GA05 Use of engineering tools

GA06 Individual and team work

GA07 Communication skills

GA08 Professionalism

GA09 Impact of engineering on society and the environment

GA10 Ethics and equity

GA11 Economics and project management

GA12 Life-long learning 


\subsubsection{Standard course outlines}

The Faculty of Engineering and Applied Science at Memorial University has implemented a standard course outline. This outline provides guidance for required elements and suggestions for sharing optional information.

As a required element, learning outcomes are shared with students in the outline. As faculty members develop their outlines, attention is focused on developing or updating course outcomes. It has also served to familiarize students with the concept of an outcome-based program. There are sections for informing students about course requirements and expectations, scheduling, assessments, issues of ethics, equity and academic integrity. As work on the curriculum database progresses, standard sections of the outline will be populated from the database and faculty will update and modify the remaining sections according to their own specifications.

\subsection{Supporting Teaching, Learning and Assessment of Graduate attributes with Online Modules}

Modules are being developed to support the instruction and assessment of graduate attributes such as individual and teamwork, communications and professionalism. These modules will be offered online and students will complete them while on work term or at other appropriate points in the program.

The modules will be available for ongoing reference. Students will be able to refer back to communications modules as they work on papers throughout the program. Faculty will be able to incorporate these learning modules in their courses to support instruction. For example, in a senior design course where teamwork is common, a faculty member may choose to incorporate a teamwork module.

\subsection{Conclusion}

Developing learning outcomes and assessments, creating links to graduate attributes and mapping the curriculum has provided Memorial's Faculty of Engineering and Applied Science with the opportunity to reflect on best practices in teaching and learning. As faculty come together to describe what students will know, or be able to do, upon completion of a course, how best to instruct and measure learning becomes part of the process.

Faculty, staff and students in Process Engineering have been working together to develop new and creative ways of instructing and assessing. This model

CEEA13; Paper 43 of collaboration is now being implemented across all engineering disciplines.

At Memorial University we are using the outcomes based approach to accreditation as an opportunity to enhance our understanding of teaching and learning, to be intentional and transparent about how we are developing graduate attributes, and to institute a process that will facilitate continuous improvement.

This is an ongoing process with significant work remaining before our vision is fully realized. Despite the long road ahead, it is clear that the CEAB's outcomes based approach to accreditation has created an opportunity for Canadian engineering faculties to make significant and positive changes to teaching and learning practices.

\section{References}

[1] Engineers Canada, Canadian Engineering Accreditation Board, "2010 Accreditation Criteria and Procedures", www.engineerscanada.ca, 2010.

[2] Simon C. Barrie, "A research-based approach to generic graduate attributes policy." Higher Education Research \& Development, 31:1, 79-92, 2012.

[3] Harden, R. M. (2001). AMEE Guide No. 21: Curriculum mapping: a tool for transparent and authentic teaching and learning. Medical Teacher, 23(2), 123-137.

[4] David R. Krathwohl, “A Revision of Bloom's

Taxonomy: An Overview," Theory Into

Practice, 41:4, 212-218, 2002.

[5] L. W. Anderson and D.R. Krathwohl, (eds.), A taxonomy for learning, teaching, and assessing: A revision of Bloom's taxonomy of educational objectives. NewYork:

AddisonWesley Longman, 2001.

[6] A comprehensive framework for teaching and learning at Memorial University, May 10, 2011. Available as of May 14, 2012 from

http://www.delts.mun.ca/faculty/teachinglearning/TLF_May _2011_FINAL_Framework.pdf

[7] M.D. Cox, "Introduction to Faculty Learning Communities ", New Directions for Teaching and Learning, vol. 2004, no. 97, pp. 5-23, 2004.

[8] O.A.B. Hassan, Learning theories and assessment methodologies - an engineering educational perspective," European Journal of Engineering Education, 36:4, 327-339, 2011. 